\title{
Pulmonary Rehabilitation Outcomes after Single or Double Lung Transplantation in Patients with Chronic Obstructive Pulmonary Disease or Interstitial Lung Disease
}

\author{
Tessa Schneeberger ${ }^{a, b}$ Rainer Gloeckl ${ }^{b, c}$ Tobias Welte ${ }^{d}$ Klaus Kenn ${ }^{a, b}$ \\ a Department of Pulmonary Rehabilitation, Philipps University of Marburg, German Center for Lung Research (DZL), \\ Marburg, ${ }^{b}$ Department of Respiratory Medicine and Pulmonary Rehabilitation, Schön Klinik Berchtesgadener Land, \\ Schönau am Königssee, 'Department of Prevention, Rehabilitation and Sports Medicine, Klinikum rechts der Isar, \\ Technical University Munich (TUM), Munich, and d Department of Respiratory Medicine, Hannover Medical School \\ and Member of the German Centre for Lung Research (DZL), Hannover, Germany
}

\section{Keywords}

Lung transplantation - Chronic obstructive pulmonary disease $\cdot$ Interstitial lung disease $\cdot$ Pulmonary rehabilitation $\cdot$ Exercise training

\begin{abstract}
Background: Pulmonary rehabilitation (PR) following lung transplantation (LTx) has been shown to be effective with regard to exercise capacity and health-related quality of life (HRQL). However, outcome data is limited with respect to LTx as a population. Differences concerning the effects of PR in patients with single LTx (SLTx) or double LTx (DLTx) have not been studied yet. Objectives: The aim was to compare possible differences concerning PR outcomes between SLTx and DLTx. Methods: In a retrospective analysis (period: 1997-2016), data from 722 patients with either chronic obstructive pulmonary disease (COPD; SLTx: $n=129, \mathrm{FEV}_{1} 51 \pm$ 17\% pred.; DLTx: $n=204, \mathrm{FEV}_{1} 74 \pm 20 \%$ pred.) or interstitial lung disease (ILD; SLTx: $n=135$, FVC $58 \pm 18 \%$ pred.; DLTx: $n=254$, FVC $63 \pm 18 \%$ pred.) after LTx were included. All patients underwent a specialized inpatient PR program. The data of the 6-minute walk distance (6MWD) and HRQL (physical [PCS] and mental [MCS] component summary of the SF-
\end{abstract}

\section{KARGER}

(C) 2017 S. Karger AG, Basel

E-Mail karger@karger.com

www.karger.com/res
36 questionnaire) were analyzed. Results: Independently from the procedure and pretransplant diagnosis, patients significantly $(p<0.05)$ improved the 6MWD without any differences between SLTx and DLTx (COPD: SLTx: $+109 \pm 68 \mathrm{~m}$, DLTx: $+117 \pm 82$ m; ILD: SLTx: $+115 \pm 80$ m, DLTx: $+132 \pm$ $77 \mathrm{~m})$. The PCS (COPD: SLTx: $+9 \pm 9$ points, DLTx: $+7 \pm 9$ points; ILD: SLTx: $+6 \pm 9$ points, DLTx: $+9 \pm 9$ points) and MCS (COPD: SLTx: $+8 \pm 15$ points, DLTx: $+7 \pm 15$ points; ILD: SLTx: $+10 \pm 13$ points, DLTx: $+8 \pm 12$ points) also improved significantly without any group differences. Conclusions: LTx patients with a pretransplant diagnosis of COPD or ILD all benefitted significantly and with clinical relevance with regard to exercise capacity and HRQL from an inpatient PR performed within 1 year postoperatively. PR outcomes were similar regardless of SLTx or DLTx.

(C) 2017 S. Karger AG, Basel

\section{Introduction}

Lung transplantation (LTx) can be an ultima ratio treatment in patients with end-stage lung diseases to improve quality of life and survival rates in selected patients [1]. Between January 1995 and June 2013, approximately 40,000
Tessa Schneeberger

Department of Respiratory Medicine and Pulmonary Rehabilitation Schön Klinik Berchtesgadener Land, Malterhöh 1

DE-83471 Schönau am Königssee (Germany)

E-Mail TSchneeberger@Schoen-Kliniken.de 
LTx procedures were performed worldwide. The largest group of LTx candidates consisted of patients with chronic obstructive pulmonary disease (COPD, 33\%) followed by interstitial lung disease (ILD, 24\%) [2]. Forty-eight percent of these COPD patients received a single LTx (SLTx) and $52 \%$ a double LTx (DLTx). A similar distribution was observed for ILD (53\% SLTx vs. 47\% DLTx) [2].

The fact that the donor block can be used either for 1 patient or can be split for 2 recipients makes the LTx surgery special [1]. A recently published study showed that patients with ILD after DLTx had a better graft survival than those after SLTx, but for COPD patients, there was no difference found [3]. However, a lack of randomized controlled trials and the great differences usually occurring within the patient populations used in such studies (e.g., heterogeneity of pretransplant diagnosis in the same study cohort) make an interpretation difficult. To this end, a current statement of the American Thoracic Society and European Respiratory Society concludes that lack of evidence concerning the beneficial nature of DLTx in comparison to SLTx exits [4].

There is evidence that pulmonary rehabilitation (PR) post-LTx surgery increases physical exercise capacity and health-related quality of life (HRQL) [5]. Despite the well-documented persisting physical impairments and the general belief that exercise training has potential for both short- and long-term benefits in this population, it should be noted that the number of studies in this particular field is still quite small, and available data is limited $[1,5]$. Up to now, there are only 3 randomized controlled trials and 1 systematic review describing the effects of PR after LTx [5]. Although pulmonary function recovers after LTx, patients cannot evolve their full potential [6, 7]. Williams et al. [7] investigated maximal exercise capacity in SLTx and DLTx recipients and showed that despite a considerable difference in postoperative pulmonary function (DLTx $>$ SLTx), the exercise capacity seems to be similar between the groups. To our knowledge, differences and benefits with regard to the shortterm outcomes of PR for SLTx and DLTx have not been studied yet.

Due to the impossibility of performing randomized trials to investigate the benefits of SLTx and DLTx, a recently published systematic review by Puri et al. [1] has concluded that more retrospective analyzes of LTx registry data would be an important source of information. Thus, the aim of this retrospective analysis was to evaluate PR outcomes and investigate if there were procedural differences concerning PR response in LTx recipients within the first year after SLTx or DLTx.

PR Outcomes after SLTx or DLTx in

COPD or ILD Patients

\section{Methods}

\section{Study Population}

In this retrospective analysis, all LTx patients who were referred to our specialized rehabilitation center (Schoen Klinik Berchtesgadener Land, Schoenau, Germany) by 12 cooperating German and 2 Austrian transplant centers between July 1997 and February 2016 were screened. To be included in the final analysis, patients had to meet the following criteria: SLTx or DLTx, pretransplant diagnosis: COPD or ILD and referral to PR $\leq 1$ year after LTx. Patients after retransplantation were excluded. A total of 722 patients were included for analysis (COPD: SLTx, $n=129$; DLTx, $n=204$; ILD: SLTx, $n=135$; DLTx, $n=254$ ). Because of the distinct pathogenesis of the pretransplant diagnosis regarding mechanisms of respiratory limitations, the analysis was split into COPD and ILD patients.

It should also be taken into consideration that each participant constitutes a complex case and that this analysis should be regarded as a real-life study. Subject demographics are shown in Table 1.

\section{Intervention: PR Program}

Patients performed a comprehensive multimodal and multidisciplinary inpatient PR program (overall average duration of 6 weeks) especially developed for patients after LTx. The program was provided on 5-6 days per week and consisted of 5-6 exercise training sessions per week. In the absence of comparative studies and sufficient evidence, general recommendations for exercise training interventions were followed. In addition to physiotherapist-supervised sessions of endurance training on cycle ergometers for $10-20 \mathrm{~min}$ at $60 \%$ of the peak work rate determined by an incremental cycle test, patients received individually tailored strength training of 4 to 6 exercises with $3 \times 20$ repetitions at the maximum tolerated load primarily targeted to the lower extremities. Training sessions lasted for 40-50 min, and postsurgical exercise precautions were always taken into account (for more information, see online suppl. SDC Table 1; for all online suppl. material, see www. karger.com/doi/10.1159/000477351). Exercise intensity and duration was progressed if possible with the aim to achieve dyspnea and leg fatigue scores between 5 and 6 on a 10-point Borg scale. Furthermore, patients performed individual sessions of breathing exercises (e.g., pursed lips breathing, diaphragmatic breathing) and practicing activities of daily life (e.g., stair climbing) supervised by experienced physiotherapists. Patients also took part in structured education sessions including LTx-specific topics; e.g., the proper use of medication, general counseling, motivation for high levels of physical activity, nutritional education, and the practice of hygiene procedures. Psychological support was offered if necessary.

\section{Hypothesis}

The primary hypothesis was that LTx patients, independently of the LTx procedure (SLTx/DLTx), show comparable effects concerning their short-term PR outcomes, including exercise capacity and HRQL after performing a comprehensive inpatient PR within the first year after surgery.

\section{Outcome Parameters}

Six-minute walk distance (6MWD) and health-related quality of life (physical [PCS] and mental [MCS] component summary of the SF-36 health survey) were evaluated as primary outcomes. The patients perceived levels of dyspnea/leg fatigue during the $6 \mathrm{MWD}$,

Respiration 2017;94:178-185 
Table 1. Baseline data of 722 patients after lung transplantation

\begin{tabular}{|c|c|c|c|c|c|c|}
\hline \multirow[t]{2}{*}{ Parameter } & \multicolumn{3}{|c|}{$\operatorname{COPD}(n=333)$} & \multicolumn{3}{|c|}{$\operatorname{ILD}^{*}(n=389)$} \\
\hline & SLTx & DLTx & $p$ value & SLTx & DLTx & $p$ value \\
\hline Number of patients & $129(38.7)$ & $204(61.3)$ & $<0.001^{\mathrm{a}}$ & $135(34.7)$ & $254(65.3)$ & $<0.001^{\mathrm{a}}$ \\
\hline Female & $76(58.9)$ & $94(46.1)$ & $0.025^{\mathrm{b}}$ & $55(40.7)$ & $101(39.7)$ & $0.914^{\mathrm{b}}$ \\
\hline Age, years & $58.8 \pm 4.8$ & $54.1 \pm 7.4$ & $<0.001^{\mathrm{c}}$ & $58.2 \pm 7.2$ & $53.6 \pm 8.7$ & $<0.001^{\mathrm{c}}$ \\
\hline BMI & $21.9 \pm 3.4$ & $21.0 \pm 3.7$ & $0.021^{\mathrm{c}}$ & $23.0 \pm 3.6$ & $21.7 \pm 3.7$ & $0.001^{\mathrm{c}}$ \\
\hline $\mathrm{FEV}_{1}, \%$ pred. & $51.1 \pm 16.6$ & $73.7 \pm 20.1$ & $<0.001^{\mathrm{c}}$ & $60.2 \pm 18.9$ & $65.6 \pm 18.1$ & $0.007^{\mathrm{c}}$ \\
\hline FVC, \% pred. & $62.1 \pm 14.7$ & $66.9 \pm 16.6$ & $0.006^{\mathrm{c}}$ & $58.4 \pm 17.5$ & $63.1 \pm 17.6$ & $0.019^{c}$ \\
\hline TLC, \% pred. & $117.0 \pm 19.9$ & $95.4 \pm 18.1$ & $<0.001^{\mathrm{c}}$ & $69.2 \pm 14.6$ & $79.2 \pm 14.9$ & $<0.001^{\mathrm{c}}$ \\
\hline $\mathrm{PaO}_{2}, \mathrm{~mm} \mathrm{Hg}$ & $71.6 \pm 10.9$ & $75.8 \pm 10.7$ & $0.001^{\mathrm{c}}$ & $70.9 \pm 10.4$ & $77.8 \pm 10.8$ & $<0.001^{\mathrm{c}}$ \\
\hline $\mathrm{PaCO}_{2}, \mathrm{~mm} \mathrm{Hg}$ & $36.9 \pm 5.8$ & $37.4 \pm 5.2$ & $0.462^{\mathrm{c}}$ & $35.3 \pm 4.7$ & $33.7 \pm 4.8$ & $0.004^{c}$ \\
\hline \multicolumn{7}{|l|}{ Duration between LTx-surgery } \\
\hline and PR admission, days & $49.1 \pm 47.3$ & $66.2 \pm 60.2$ & $0.004^{\mathrm{c}}$ & $59.7 \pm 58.1$ & $58.5 \pm 50.0$ & $0.839^{c}$ \\
\hline PR duration, days & $39.6 \pm 17.6$ & $38.2 \pm 16.4$ & $0.483^{\mathrm{c}}$ & $40.0 \pm 15.9$ & $40.9 \pm 18.2$ & $0.625^{\mathrm{c}}$ \\
\hline $6 \mathrm{MWD}^{\S}, \mathrm{m}$ & $269.8 \pm 108.3$ & $296.7 \pm 139.2$ & $0.070^{\mathrm{c}}$ & $280.3 \pm 153.1$ & $277.5 \pm 143.3$ & $0.868^{c}$ \\
\hline SF-36 PCS ${ }^{\S \varsigma}$, pts. & $29.3 \pm 7.5$ & $29.7 \pm 11.5$ & $0.803^{c}$ & $34.3 \pm 9.2$ & $25.7 \pm 10.3$ & $<0.001^{\mathrm{c}}$ \\
\hline SF-36 MCS ${ }^{\$ \varsigma}$, pts. & $42.4 \pm 16.7$ & $41.9 \pm 16.5$ & $0.864^{\mathrm{c}}$ & $37.9 \pm 15.5$ & $42.1 \pm 15.2$ & $0.107^{c}$ \\
\hline
\end{tabular}

Data are presented as mean \pm SD or $n(\%)$. COPD, chronic obstructive pulmonary disease; ILD, interstitial lung disease; DLTx, double lung transplantation; SLTx, single lung transplantation; LTx, lung transplantation; PR, pulmonary rehabilitation; 6MWD, 6-minute walk distance; PCS, physical component summary; MCS, mental component summary; pts., points. ${ }^{\S}$ COPD: $\operatorname{SLTx}(n=108)$, DLTx $(n=178)$; ILD: SLTx $(n=117)$, DLTx: $(n=217) ;{ }^{\S}$ COPD: SLTx $(n=45)$, DLTx $(n=75)$; ILD: SLTx $(n=53)$, DLTx $(n=123)$ * Subgroups ILD: SLTx: usual interstitial pneumonia [UIP]/idiopathic pulmonary fibrosis [IPF] 84\%, extrinsic allergic alveolitis [EAA] 10\%, others 6\%; DLTx: UIP/IPF 69\%, EAA $15 \%$, others $16 \%$. ${ }^{\mathrm{a}} \chi^{2}$ test; ${ }^{\mathrm{b}}$ Fisher exact test; ${ }^{\mathrm{c}}$ independent $t$ test.

and adverse events including infection or acute rejection during PR were analyzed as secondary outcomes.

\section{Measurements}

Exercise Capacity - 6MWD

Until 2002, the 6MWD was ascertained according to a standardized protocol [8], both on admission and at discharge of PR. Since then, the 6MWD has been performed based on the current guidelines of the American Thoracic Society of 2002 and 2014 [9, 10]. Investigators who performed 6-minute walk tests (6MWTs) were well instructed which provided a high level of standardization. The modified Borg scale (0 [none] to 10 [maximum] impairment) was used to rate perceived levels of dyspnea and leg fatigue at rest and at the end of the test.

\section{HRQL - SF-36}

This patient self-reported short-form health survey was assessed on admission and discharge. Outcome parameters of the SF-36 are the PCS and MCS, which are the basic dimensions of subjective health. Both component summaries were transformed in a linear $\mathrm{T}$ score with a mean of 50 and a standard deviation of 10. These values are based on the analysis of the US-norm sample of 1990 . Values $>60$ are above the average, and values $<40$ are below the average [11].

Adverse Events during PR

Within the first year after LTx surgery, viral (mostly cytomegalovirus, defined as the detection of the cytomegalovirus pp65 anti- gen in leukocytes) or bacterial infection and acute organ rejection are among the most common complications $[12,13]$. Based on the patients' medical files, it was possible to detect if patients showed any of these adverse events during PR. Patient files were checked for antibiotic treatment for $>5$ days, newly introduced intravenous or high-dose oral virostatic treatment, or organ rejection therapy.

Lung Function

Spirometry and body plethysmography (MasterScreen Body; Jaeger $\mathrm{GmbH}$, Hoechberg, Germany) was performed following the guidelines of the American Thoracic Society [14, 15].

\section{Statistical Analysis}

Statistical analysis was done utilizing SPSS (Version 23 IBM SPSS). Because of the exploratory nature of this study, a two-sided significance level was determined at $p \leq 0.05$ for all testing. Baseline data is presented as mean with standard deviations. The independent $t$ test and $\chi^{2}$ or Fisher exact test was used to compare descriptive data at baseline. The data of the 6MWD and SF-36 were analyzed with dependent/independent $t$ tests. Data are presented as mean with standard deviations. Ordinal data such as the Borg scale were analyzed with nonparametric tests as the Wilcoxon and Mann-Whitney U test. Furthermore, a one-way analysis of variance (ANOVA) was performed. This procedure was also used in order to look for possible outcome variability during the study time period. To quantify possible coherences between particular parameters and the change in exercise capacity and HRQL during $\mathrm{PR}$, linear regression analyses were executed.
180

Respiration 2017;94:178-185

DOI: $10.1159 / 000477351$
Schneeberger/Gloeckl/Welte/Kenn 


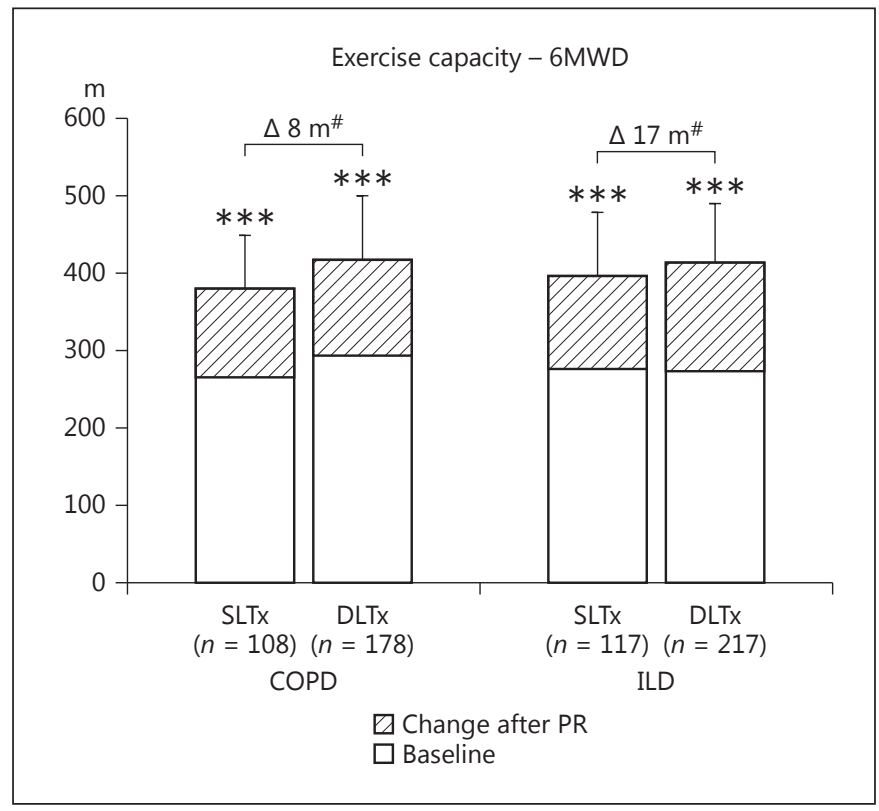

Fig. 1. Baseline value (mean) and change $(\Delta$ mean $\pm \mathrm{SD})$ in the 6-minute walk distance (6MWD) after pulmonary rehabilitation (PR) in patients with chronic obstructive pulmonary disease (COPD) and interstitial lung disease (ILD) following single (SLTx) or double lung transplantation (DLTx). ${ }^{* * *} p \leq 0.001$; $^{\#} p>0.05$.

\section{Results}

Subject demographics of all 722 patients are shown in Table 1. Complete 6MWD (admission and discharge PR) data were available for 620 patients. Complete SF-36 data were available only in 296 patients due to incomplete or invalid questionnaires. Reasons for missing data and dropouts are shown in the online supplementary digital content (SDC), Figure 1 and SDC Table 2.

\section{PR Outcome Data in LTx Patients due to COPD}

Patients after SLTx as well as DLTx were able to improve the 6MWD (SLTx, $+109 \pm 68 \mathrm{~m}$; DLTx,$+117 \pm$ $82 \mathrm{~m}$ ) and HRQL (SLTx, PCS: $+9 \pm 9$ points/MCS: $+8 \pm$ 15 points; DLTx, PCS: $+7 \pm 9$ points/MCS: $+7 \pm 15$ points) statistically significantly $(p \leq 0.001)$ after PR. Improvements in the 6MWD and HRQL did not show a significant difference $(p>0.05)$ between SLTx and DLTx (Fig. 1, 2 ). Changes regarding dyspnea and leg muscle fatigue at the end of the 6MWD also did not differ between the groups (online suppl. [SDC], Table 3). There were also no significant differences regarding the adverse event rate during PR (infection: SLTx, $n=27$ [20.9\%]; DLTx, $n=38$ [18.6\%], $p=0.671$; acute rejection: SLTx, $n=4$ [3.1\%]; DLTx, $n=7$ [3.4\%], $p=1.000$ ).

PR Outcomes after SLTx or DLTx in COPD or ILD Patients
PR Outcome Data in LTX Patients due to ILD

Both groups showed highly significant improvements in the 6MWD (SLTx, $115 \pm 79 \mathrm{~m}$; DLTx, $132 \pm 77 \mathrm{~m}$ ) and SF-36 summary scores (SLTx, PCS: $6 \pm 9$ points/MCS: 10 \pm 12 points; DLTx, PCS: $9 \pm 9$ points/MCS: $8 \pm 12$ points) after PR. Improvement in the 6MWD was not significantly different between SLTx and DLTx $(p=0.056)$; however, patients after DLTx were able to increase $6 \mathrm{MWD}$ by $17 \pm 9 \mathrm{~m}$ more than SLTx patients (Fig. 1,2). Based on the Borg scale, changes in dyspnea and leg fatigue at the end of the 6MWT did not differ between the groups (see online suppl. [SDC] Table 3).

As could be seen in the COPD group, there were no statistical differences in the adverse event rate considering the LTx procedure during PR in ILD patients (infection: SLTx, $n=34$ [25.2\%]; DLTx, $n=55$ [21.7\%], $p=$ 0.448; acute rejection: SLTx, $n=5$ [3.7\%]; DLTx, $n=5$ [2.0\%], $p=0.326)$.

\section{ANOVA}

ANOVA showed that the LTx procedure did not have a significant influence on the improvement of the 6MWD $(p=0.056)$ or HRQL (PCS: $p=0.756$; MCS: $p=0.510)$. Thus, regardless of the underlying LTx procedure, all patient groups were able to improve exercise capacity and HRQL equally. There was also no influence on dyspnea $(p=0.749)$ and leg fatigue $(p=0.563)$ at the end of 6MWT. The pretransplant diagnosis (COPD or ILD) showed no significant effect on $6 \mathrm{MWD}(p=0.117)$, PSC $(p=0.302)$, MSC $(p=0.341)$, dyspnea $(p=0.988)$, or leg fatigue $(p=$ $0.110)$. However, the LTx procedure $\left(\mathrm{FEV}_{1}: p \leq 0.001\right.$; FVC: $p=0.004)$ and the pretransplant diagnosis $\left(\mathrm{FEV}_{1}\right.$ : $p \leq 0.001$; FVC: $p \leq 0.001)$ showed a highly significant influence on pulmonary function. Patients after DLTx (due to COPD or ILD) and COPD patients in general were able to achieve greater improvements in pulmonary function parameters during PR. Grouping by gender or time between LTx and PR admission did not have a statistically significant effect on the outcomes $(p>0.05)$. For time between LTx and PR admission, patients were clustered into 3 groups according to the time between LTx surgery and PR admission: (1) 0-90 days after LTx; (2) 91-180 days after LTx; (3) 181-365 days after LTx.

\section{Linear Regression Analysis}

Finally, it was evaluated whether changes in exercise capacity (6MWD) and HRQL (PCS and MCS) had been coherent in different factors such as LTx procedure, underlying disease, age, sex, BMI, and time between LTx surgery and PR admission. Since the different models

Respiration 2017;94:178-185 181 


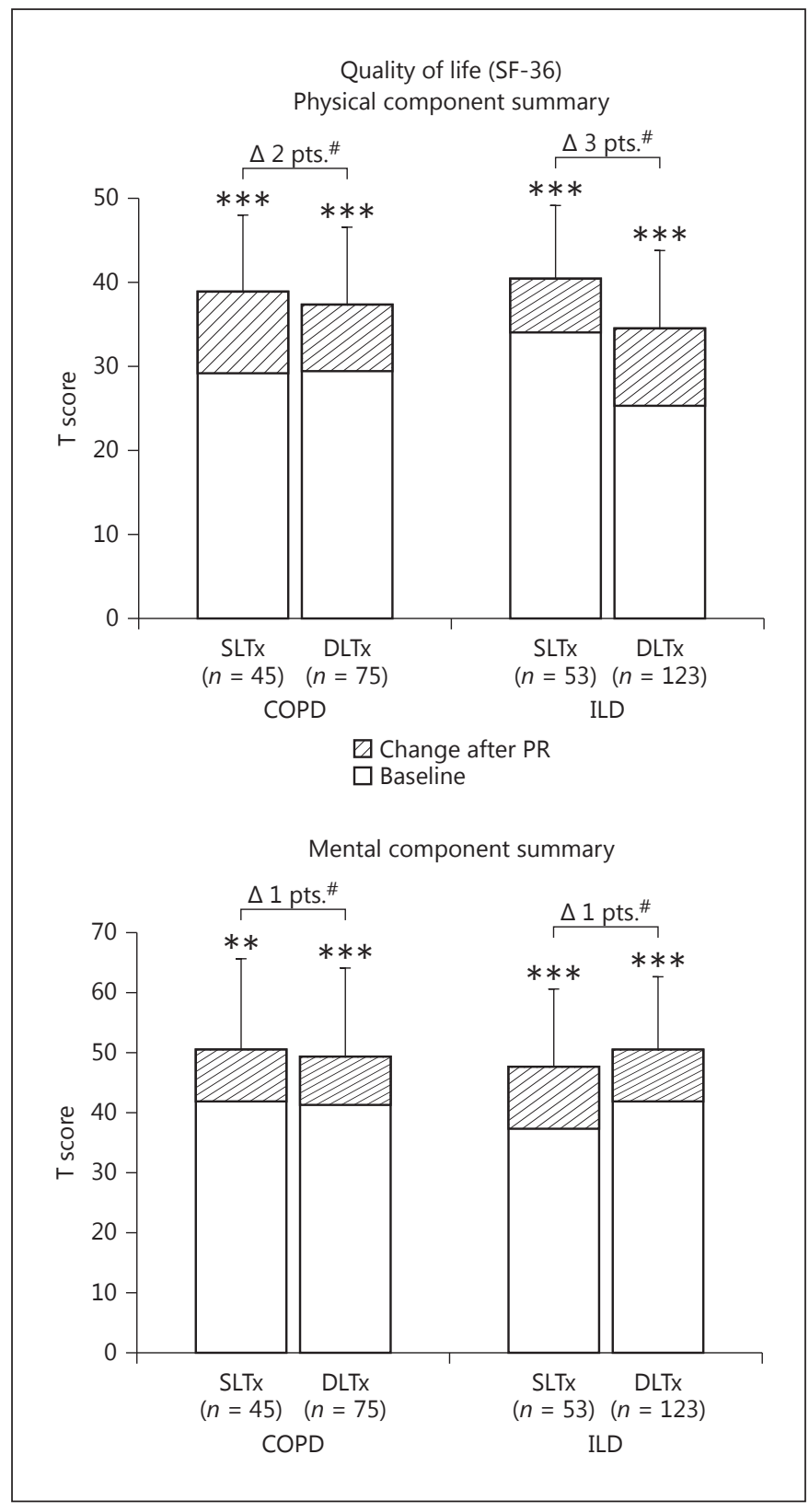

Fig. 2. Baseline value (mean) and change ( $\Delta$ mean \pm SD) in physi$\mathrm{cal} /$ mental component summary after pulmonary rehabilitation in patients with chronic obstructive pulmonary disease (COPD) and interstitial lung disease (ILD) following single (SLTx) or double lung transplantation (DLTx). pts., points. ${ }^{* *} 0.01 \geq p>0.001$; *** $p \leq 0.001 ;{ }^{\#} p>0.05$.

only explain $5 \%$ or less of the variance of changes in 6MWD and HRQL, no further analyses was performed. Thus, with regard to all outcome parameters mentioned above, no clinically relevant predictors for changes in the $6 \mathrm{MWD}$ or SF-36 health survey could be identified.

\section{Discussion}

The novel findings of this study are that irrespective of the LTx procedure or the pretransplant diagnosis, patients who completed a specialized PR program within the first year after LTx showed similarly significant and clinically relevant improvements in exercise capacity and HRQL. COPD and ILD patients seem to respond to PR to a similar extent regardless of their LTx procedure.

Evidence stating that specialized PR, especially exercise training after LTx, increases functional exercise capacity and HRQL [16-21], is in line with our study.

The baseline characteristics, especially with regard to differences in age between the 2 LTx modalities, were in line with previously published data [22-25]. COPD patients after SLTx started PR on average 2.5 weeks earlier than COPD patients after DLTx surgery. This could be due to the minor surgical trauma of SLTx surgery. However, no statistical impact was found due to the shorter duration between LTx surgery and PR admission on the 6MWD or HRQL.

\section{Exercise Capacity - 6MWD}

The overall increase in 6MWD for both COPD and ILD patients, independent of the LTx procedure, was considerably above the suggested minimal important difference of $25-33 \mathrm{~m}$ in chronic respiratory diseases [26]. Furthermore, there was no clinically relevant difference in the 6MWD improvement between SLTx and DLTx in COPD patients $(\Delta 8 \mathrm{~m})$ or in ILD patients $(\Delta 17 \mathrm{~m})$. Although patients in all groups walked longer distances at the end of PR, they perceived less muscle fatigue at the end of the 6MWT, which reflects a positive physical adaption to exercise training. Improvements in the $6 \mathrm{MWT}$ were comparable with data from Maury et al. [20] who observed an increase in functional exercise tolerance in 36 patients $(+140 \pm 91 \mathrm{~m})$, with COPD or ILD after LTx surgery, which was also not different between SLTx and DLTx. A recently published randomized controlled study investigated the effects of a supervised longer (14-week) versus shorter (7-week) duration of the PR program after LTx. Unlike the assumed hypothesis, a longer duration did not result in superior outcomes for the 6MWD and SF-36 component summary scores compared to a shorter duration of $\mathrm{PR}$, even at 6 months post LTx [27]. This can be seen as a hint that the average duration of 6 weeks in our study also elicited meaningful improvements in exercise capacity and HRQL. 
Health-Related Quality of Life - SF-36

Improvements in HRQL were comparable for SLTx and DLTx in COPD and ILD-patients. Even though on admission, ILD patients after SLTx showed higher PCS scores than after DLTx; there was no significant influence on the increase during PR. Although, there is no minimal important difference established yet for clinically meaningful changes in SF-36 in LTx patients, we assumed that the statistically significant improvements for both summary scores were of clinical importance. Overall, LTx patients achieved mean differences clearly $>2$ points on PCS and MCS, which is considered to be clinically and psychosocially relevant [11]. Furthermore, both patient groups, independent of the LTx procedure, achieved MCS results that correspond to age- and gender-matched values of healthy subjects [11].

Finlen Copeland et al. [28] showed that during the first year after LTx, PCS significantly increased (COPD: +10.2 points; IPF: +7.2 points), reflecting the natural recovery after transplantation. Neither the pretransplant diagnosis nor the LTx procedure was significantly associated with different improvements in PCS, which is in line with our findings.

However, in contrast to these findings, our data showed that even MCS increased markedly after PR and obtained values comparable to healthy subjects. This may be seen as a hint that PR positively influences mental health in these patients beyond the natural recovery.

\section{Spirometry and Adverse Events}

As other studies already have shown, DLTx patients generally showed better post-transplantation pulmonary function compared to SLTx [29, 30]. Mason et al. [30] analyzed the postoperative $\mathrm{FEV}_{1}$ and FVC of $463 \mathrm{LTx}$ patients. With regard to the limited number of lifesaving organs, he concluded that the slightly higher values in pulmonary function alone may not justify the preference of the DLTx surgery. Bartels et al. [6] and Williams et al. [7] showed that although considerable differences in pulmonary function remain, the maximal exercise performance does not differ between the LTx procedures. Langer et al. [31] even observed trends towards a better leg muscle force, exercise capacity, and daily physical activity in SLTx recipients despite better lung function in DLTx recipients.

This similarity to our results might suggest that exercise performance after SLTx and DLTx is not only determined by respiratory factors, but rather more by a decline in skeletal muscle performance, which does not recover spontaneously $[6,7]$.

PR Outcomes after SLTx or DLTx in COPD or ILD Patients
Adverse event rates including bacterial or viral infections as well as acute organ rejections during inpatient PR were comparable between SLTx and DLTx. Additionally, we did not see adverse events that were related to exercise training. Thus, PR seems to be safe in this specific cohort.

\section{Limitations}

There are some limitations that need to be addressed. Firstly, due to the retrospective design of our analysis, data have been collected over a period of 19 years. Despite this, an analysis of the outcome parameters scaled in 5 groups (years 1997-2000; 2001-2004; 2005-2008; 20092012; 2013-2016) showed that there was no significant difference over the total trial period. Secondly, because of the lack of a control group, it is not possible to preclude effects due to the natural recovery after LTx. Therefore, it is not possible to associate improvements in functional exercise capacity and HRQL only to the PR program. Thirdly, the amount of missing SF-36 and 6MWD data may have led to a bias in these outcomes.

Finally, one has to consider, that these data only represent short-term effects of PR. Long-term effects could not be collected from our cohort.

\section{Potential Clinical Relevance}

Due to the shortage of donor organs, the allocation of available organs to the most appropriate recipients remains a very difficult decision for transplant centers. There is an increasing number of DLTx in COPD and ILD recipients [2] and a lingering uncertainty whether SLTx actually has similar outcomes as DLTx [4]. Consequently, there is an ongoing debate about finding a balance between achieving the best possible LTx outcome on the one hand and considering ethical aspects such as allocating a donor lung to 1 or 2 patients on the other. A future comparison of all aspects of outcomes of SLTx or DLTx between well-matched recipient groups will help to better define the respective roles of these procedures.

\section{Conclusion}

In summary, these results show that COPD and ILD patients after LTx benefit to a significant and clinically relevant extent from a specialized, comprehensive inpatient PR. With regards to improvements in exercise capacity, HRQL, and the frequency of adverse events during PR, there were no significant differences between SLTx and DLTx. It seems that SLTx and DLTx patients are trainable to a similar benefit within the first year after surgery.

Respiration 2017;94:178-185 
Further prospective studies concerning the long-term effects of PR after SLTx and DLTx and their potential influence on the prognosis of LTx recipients are needed.

\section{Financial Disclosure and Conflicts of Interest}

The authors declare that there are no conflicts of interest to disclose.

\section{Author Contributions}

T.S. and R.G. contributed equally to the preparation of this article. T.S. participated in the research design, data analysis, and writing of the article. R.G. shared the scientific discussion and contributed in the writing of the article. T.W. shared the scientific discussion and was involved in the writing of the article. K.K. participated in the research design, shared the scientific discussion, and was involved in the writing of the article.

\section{References}

1 Puri V, Patterson GA, Meyers BF: Single versus bilateral lung transplantation: do guidelines exist? Thorac Surg Clin 2015;25: 47-54.

2 Yusen RD, Edwards LB, Kucheryavaya AY, Benden C, Dipchand AI, Dobbels F, Goldfarb SB, Levvey BJ, Lund LH, Meiser B, Stehlik J; International Society for Heart and Lung Transplantation: The registry of the international society for heart and lung transplantation: thirty-first adult lung and heart-lung transplant report-2014; focus theme: retransplantation. J Heart Lung Transplant 2014;33: 1009-1024.

3 Schaffer JM, Singh SK, Reitz BA, Zamanian RT, Mallidi HR: Single- versus double-lung transplantation in patients with chronic obstructive pulmonary disease and idiopathic pulmonary fibrosis since the implementation of lung allocation based on medical need. JAMA 2015;313:936-948.

4 Celli BR, Decramer M, Wedzicha JA, Wilson KC, Agusti A, Criner GJ, MacNee W, Make BJ, Rennard SI, Stockley RA, Vogelmeier C, Anzueto A, Au DH, Barnes PJ, Burgel PR, Calverley PM, Casanova C, Clini EM, Cooper CB, Coxson HO, Dusser DJ, Fabbri LM, Fahy B, Ferguson GT, Fisher A, Fletcher MJ, Hayot M, Hurst JR, Jones PW, Mahler DA, Maltais F, Mannino DM, Martinez FJ, Miravitlles M, Meek PM, Papi A, Rabe KF, Roche N, Sciurba FC, Sethi S, Siafakas N, Sin DD, Soriano JB, Stoller JK, Tashkin DP, Troosters T, Verleden GM, Verschakelen J, Vestbo J, Walsh JW, Washko GR, Wise RA, Wouters EF, ZuWallack RL: An official American Thoracic Society/European Respiratory Society statement: research questions in COPD. Eur Respir J 2015;45:879-905.

5 Spruit MA, Singh SJ, Garvey C, ZuWallack R, Nici L, Rochester C, Hill K, Holland AE, Lareau SC, Man WD, Pitta F, Sewell L, Raskin J, Bourbeau J, Crouch R, Franssen FM, Casaburi R, Vercoulen JH, Vogiatzis I, Gosselink R, Clini EM, Effing TW, Maltais F, van der Palen J, Troosters T, Janssen DJ, Collins E, Garcia-Aymerich J, Brooks D, Fahy BF, Puhan MA, Hoogendoorn M, Garrod R, Schols AM, Carlin B, Benzo R, Meek P, Morgan M,
Rutten-van Molken MP, Ries AL, Make B, Goldstein RS, Dowson CA, Brozek JL, Donner CF, Wouters EF: An official American Thoracic Society/European Respiratory Society statement: key concepts and advances in pulmonary rehabilitation. Am J Respir Crit Care Med 2013;188:e13-e64.

6 Bartels MN, Armstrong HF, Gerardo RE, Layton AM, Emmert-Aronson BO, Sonett JR, Arcasoy SM: Evaluation of pulmonary function and exercise performance by cardiopulmonary exercise testing before and after lung transplantation. Chest 2011;140: 1604-1611.

7 Williams TJ, Patterson GA, McClean PA, Zamel N, Maurer JR: Maximal exercise testing in single and double lung transplant recipients. Am Rev Respir Dis 1992;145:101-105.

8 Guyatt GH, Sullivan MJ, Thompson PJ, Fallen EL, Pugsley SO, Taylor DW, Berman LB: The 6-min walk: a new measure of exercise capacity in patients with chronic heart failure. Can Med Assoc J 1985;132:919-923.

9 Holland AE, Spruit MA, Troosters T, Puhan MA, Pepin V, Saey D, McCormack MC, Carlin BW, Sciurba FC, Pitta F, Wanger J, MacIntyre N, Kaminsky DA, Culver BH, Revill SM, Hernandes NA, Andrianopoulos V, Camillo CA, Mitchell KE, Lee AL, Hill CJ, Singh SJ: An official European Respiratory Society/ American Thoracic Society technical standard: field walking tests in chronic respiratory disease. Eur Respir J 2014;44:1428-1446.

10 ATS-statement: guidelines for the six-minute walk test. Am J Respir Crit Care Med 2002; 166:111-117.

11 Bullinger M, Kirchberger I: SF-36 Fragebogen zum Gesundheitszustand. Göttingen, Hogrefe, 1998

12 Ahmad S, Shlobin OA, Nathan SD: Pulmonary complications of lung transplantation. Chest 2011;139:402-411.

13 Fuehner T, Welte T, Gottlieb J: Lung transplantation (in German). Internist (Berl) 2012; 53:567-574.

14 Wanger J, Clausen JL, Coates A, Pedersen OF, Brusasco V, Burgos F, Casaburi R, Crapo R, Enright P, van der Grinten CP, Gustafsson P, Hankinson J, Jensen R, Johnson D, Macintyre
N, McKay R, Miller MR, Navajas D, Pellegrino R, Viegi G: Standardisation of the measurement of lung volumes. Eur Respir J 2005; 26:511-522.

15 Miller MR, Hankinson J, Brusasco V, Burgos F, Casaburi R, Coates A, Crapo R, Enright P, van der Grinten CP, Gustafsson P, Jensen R, Johnson DC, MacIntyre N, McKay R, Navajas D, Pedersen OF, Pellegrino R, Viegi G, Wanger J: Standardisation of spirometry. Eur Respir J 2005;26:319-338.

16 Dierich M, Tecklenburg A, Fuehner T, Tegtbur $\mathrm{U}$, Welte T, Haverich A, Warnecke G, Gottlieb J: The influence of clinical course after lung transplantation on rehabilitation success. Transpl Int 2013;26:322-330.

17 Langer D, Burtin C, Schepers L, Ivanova A, Verleden G, Decramer M, Troosters T, Gosselink R: Exercise training after lung transplantation improves participation in daily activity: a randomized controlled trial. Am J Transplant 2012;12:1584-1592.

18 Wickerson L, Mathur S, Brooks D: Exercise training after lung transplantation: a systematic review. J Heart Lung Transplant 2010;29: 497-503.

19 Munro PE, Holland AE, Bailey M, Button BM, Snell GI: Pulmonary rehabilitation following lung transplantation. Transplant Proc 2009;41:292-295.

20 Maury G, Langer D, Verleden G, Dupont L, Gosselink R, Decramer M, Troosters T: Skeletal muscle force and functional exercise tolerance before and after lung transplantation: a cohort study. Am J Transplant 2008;8:12751281.

21 Gloeckl R, Heinzelmann I, Seeberg S, Damisch T, Hitzl W, Kenn K: Effects of complementary whole-body vibration training in patients after lung transplantation: a randomized, controlled trial. J Heart Lung Transplant 2015;34:1455-1461.

22 Thabut G, Christie JD, Ravaud P, Castier Y, Brugiere O, Fournier M, Mal H, Leseche G, Porcher R: Survival after bilateral versus single lung transplantation for patients with chronic obstructive pulmonary disease: a retrospective analysis of registry data. Lancet 2008;371:744-751. 
23 Pochettino A, Kotloff RM, Rosengard BR, Arcasoy SM, Blumenthal NP, Kaiser LR, Bavaria JE: Bilateral versus single lung transplantation for chronic obstructive pulmonary disease: intermediate-term results. Annals Thorac Surg 2000;70:1813-1818; discussion 18181819.

24 Schwaiblmair M, Reichenspurner H, Muller C, Briegel J, Furst H, Groh J, Reichart B, Vogelmeier C: Cardiopulmonary exercise testing before and after lung and heart-lung transplantation. Am J Respir Crit Care Med 1999. 159:1277-1283.

25 Bavaria JE, Kotloff R, Palevsky H, Rosengard B, Roberts JR, Wahl PM, Blumenthal N, Archer C, Kaiser LR: Bilateral versus single lung transplantation for chronic obstructive pulmonary disease. J Thorac Cardiovasc Surg 1997;113:520-527; discussion 528.
26 Singh SJ, Puhan MA, Andrianopoulos V, Hernandes NA, Mitchell KE, Hill CJ, Lee AL, Camillo CA, Troosters T, Spruit MA, Carlin BW, Wanger J, Pepin V, Saey D, Pitta F, Kaminsky DA, McCormack MC, MacIntyre N, Culver BH, Sciurba FC, Revill SM, Delafosse V, Holland AE: An official systematic review of the European Respiratory Society/American Thoracic Society: measurement properties of field walking tests in chronic respiratory disease. Eur Respir J 2014;44:1447-1478.

27 Fuller LM, Button B, Tarrant B, Steward R, Bennett L, Snell G, Holland AE: Longer versus shorter duration of supervised rehabilitation after lung transplantation: a randomized trial. Arch Phys Med Rehabil 2017;98:220-226.

28 Finlen Copeland CA, Vock DM, Pieper K, Mark DB, Palmer SM: Impact of lung transplantation on recipient quality of life: a serial, prospective, multicenter analysis through the first posttransplant year. Chest 2013;143:744750.
29 Gerbase MW, Spiliopoulos A, Rochat T, Archinard M, Nicod LP: Health-related quality of life following single or bilateral lung transplantation: a 7-year comparison to functional outcome. Chest 2005;128:1371-1378.

30 Mason DP, Rajeswaran J, Murthy SC, McNeill AM, Budev MM, Mehta AC, Pettersson GB, Blackstone EH: Spirometry after transplantation: how much better are two lungs than one? Ann Thorac Surg 2008;85:1193-1201, 1201 e1191-e1192.

31 Langer D, Gosselink R, Pitta F, Burtin C, Verleden G, Dupont L, Decramer M, Troosters T: Physical activity in daily life 1 year after lung transplantation. J Heart Lung Transplant 2009;28:572-578. 